\title{
The German Market Introduction Program for Biobased Lubricants
}

\author{
Heinrich Theissen ${ }^{*}$ \\ RWTH Aachen University, Institute for Fluid Power Drives and Controls (IFAS) \\ Steinbachstr. 53, 52074 Aachen, Germany \\ *Corresponding author: th@ifas.rwth-aachen.de \\ ( Manuscript received 8 December 2009; accepted 5 February 2010; published 15 October 2010 ) \\ (Presented at the mini-Symposium on Tribological Aspects of Fluid Power in the World Tribology Congress 2009)
}

\begin{abstract}
In order to promote biobased lubricants, the German government has supported the conversion of existing or new equipment from mineral oil to biobased oil through financial grants, technical advice, and publicity, during the years 2001 through 2008. The author has been responsible for providing technical support and scientific evaluations to the program.

$95 \%$ of the conversions were mobile hydraulic equipment and waterway installations. In an overview, market data and specifics are given, as well as typical properties of biobased hydraulic fluids, cost calculations, results of contamination experiments, and technical instructions for conversion of equipment.
\end{abstract}

Keywords: bio-oil, biolubricant, biobased, radiocarbon, market share, renewable content, renewable raw materials (RRM), contamination, flushing, conversion, European Ecolabel, lubricant, hydraulic fluid, mobile hydraulics

\section{Definitions of bio-lubricants}

There is no uniform definition for bio-lubricants, which may be biodegradable, non-toxic, biobased, or combinations thereof. The most common standard is ISO $15380^{1)}$ for hydraulic oils, supplemented by a number of ecolabels with different requirements. It is generally accepted that bio-lubricants must fulfill the OECD 301 ${ }^{2}$ test for biodegradability. Most bio-lubricants are composed of natural or synthetic esters or mixtures, and additives.

\section{The german market introduction program}

In order to promote biobased lubricants, the German government has supported the conversion of existing or new equipment from mineral oil to biobased oil through financial grants, technical advice, and publicity, during the years 2001 through 2008. The author has been responsible for providing technical support and scientific evaluations to the program.

All admitted lubricants containing at least $50 \%$ renewable carbon were listed in a Positivliste, which is available from the internet ${ }^{3)}$. This list contains approx. 250 products from 40 vendors.

More than 25,000 pieces of equipment have been converted; $95 \%$ of the conversions were mobile hydraulic equipment (e. g. construction, agricultural, forestry), hydraulic waterway installations, wind turbine gear oils, and loss lubrication greases. Mobile hydraulic machines are especially interesting applications because of the high loss risk of the fluid, given the high pressures, extended piping, and the large quantity of fluid present on the vehicle. Most of the equipment were used machines of all ages, a smaller part were new machines.

Biodegradable and biobased hydraulic fluids have been increasing their market shares during the last

Market Shares Mobile Hydraulic Fluids Germany

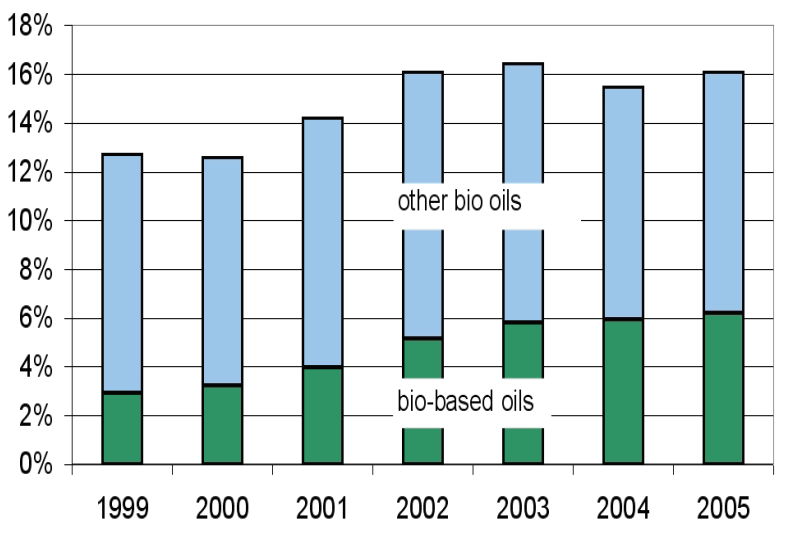

Fig. 1 Market shares of biodegradable mobile hydraulic fluid $^{4)}$ 
decade $^{4)}$. A graph for Germany as the biggest single market in Europe is given in Figure 1, showing the development of bio market shares in the fluid market for mobile hydraulic equipment.

\section{Verification methods}

In order to prevent abuse and verify if admitted products had a sufficiently high biobased content, the radiocarbon analysis method has been introduced for admission checks. The radiocarbon method is better known for age determination in archaeology, but it also allows to determine the percentages of fossil and recent biobased content through counting the number of ${ }^{14} \mathrm{C}$ isotopes in the material, independent of its chemical composition. It has recently been standardized for this purpose $^{5)}$. The method was tested in an Accelerator Mass Spectrometry (AMS) laboratory before introduction in the program, with good results as can be seen in Figure 2. The error range is approx. $+/-1 \%$, mostly due to unknown harvest dates of the materials tested.

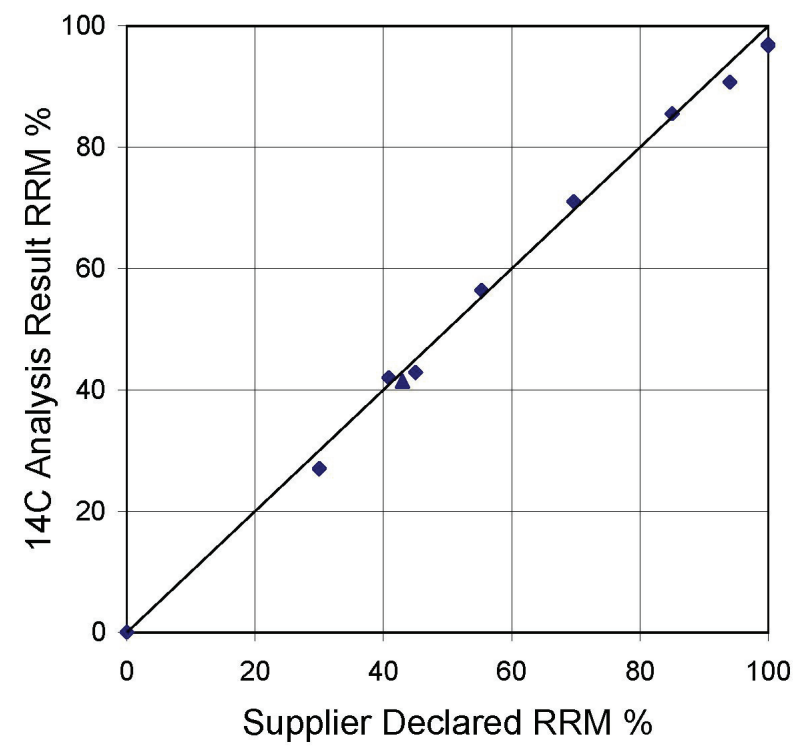

Fig. 2 Test of radiocarbon method for renewable raw material (RRM) detection

For a quick check if biodegradable oil has been filled into the vehicle, a sensor has been developed in co-operation between IFAS and a manufacturer ${ }^{6)}$ of hydraulic components to detect the presence of esters in a lubricant. There is a very high correlation between the ester content and the biodegradability of a hydraulic fluid. Esters have polarized molecules and show a different dielectrical behavior than mineral oil and polyalphaolefins (PAO). This property can easily be detected by measuring the capacitance of the fluid. The portable sensor is based on a standard oil condition monitoring sensor of that company and can be used for law enforcement in areas where (more expensive) bio-oil is mandatory, e. g. in forests certified by the Programme for the Endorsement of Forest Certification Schemes (PEFC, http://www.pefc.org/) or the Forest Stewardship Council (FSC, http://www.fsc.org/).

\section{Technical aspects}

When moving from mineral oil to bio-oil, a lower viscosity group should be considered. Esters have a higher density and a higher viscosity index than mineral oils, and a HEES32 bio fluid at a critical temperature of $100{ }^{\circ} \mathrm{C}$ has a higher viscosity than a HLP46 mineral oil.

Typical properties of biobased hydraulic fluids are excellent lubrication properties - lower friction, better viscosity index - and a somewhat higher sensitivity to oxidation and hydrolysis. The service life of an oil fill can be extended considerably through improved maintenance practices like bypass micro filtering and regular laboratory checks; this is especially meaningful when more expensive lubricants are being used.

The fluid should be kept dry to avoid hydrolysis, which can be a problem in modern pressurized hydraulic tanks. These compact systems do not allow the natural evaporation of humidity as open systems do, and may require additional filter cartridges to remove water. In an experiment with a forest tractor with severe humidity problems, water content could be reduced by 500 ppm within 60 operating hours by simply replacing the pressure lid of the hydraulic tank with a common open lid with air filter ${ }^{7)}$. This coincides with earlier laboratory experiments at IFAS to find water reduction methods ${ }^{8)}$.

\section{Mineral oil contamination and flushing}

One of the major obstacles in this market conversion is the sensitivity of biobased ester fluids or biodegradable fluids (bio-oils) to contamination with traditional mineral oil based hydraulic fluids. With biodegradable oils (both biobased and others) having a share in the range of $15-20 \%$ in the German mobile hydraulics fluid market (see fig. 1), mineral fluids are omnipresent, and there are many opportunities for contamination of bio-oil with mineral oil. Typical situations are either incomplete flushing during conversion from mineral oil to bio-oil, or lack of attention during maintenance and refilling.

With mineral oil contamination levels reaching several percent, problems like excess foam generation, poor air release, or filter clogging have been reported to the author during his supervision of the conversions. As a consequence, malfunction or even severe damage to the equipment may occur. For example, in a movable railroad bridge that had been converted in 2001, frequent filter changes were necessary during six months following the conversion, returning to normal intervals after that period.

Contaminations with mineral oil may generate reaction products and deposits, as shown in Figure 3. There is some evidence that the reaction products are not caused by the mineral base oil, but are a consequence of introducing mineral oil additives into the bio-oil ${ }^{9)}$. 
Figure 4 shows that the degree of foam generation according to the current ASTM foam test increases significantly with higher metal content, especially zinc. Ash-free mineral oil products did not cause any problems when mixed with biobased oil. The mechanisms leading to these symptoms are not yet fully understood and need further investigation.

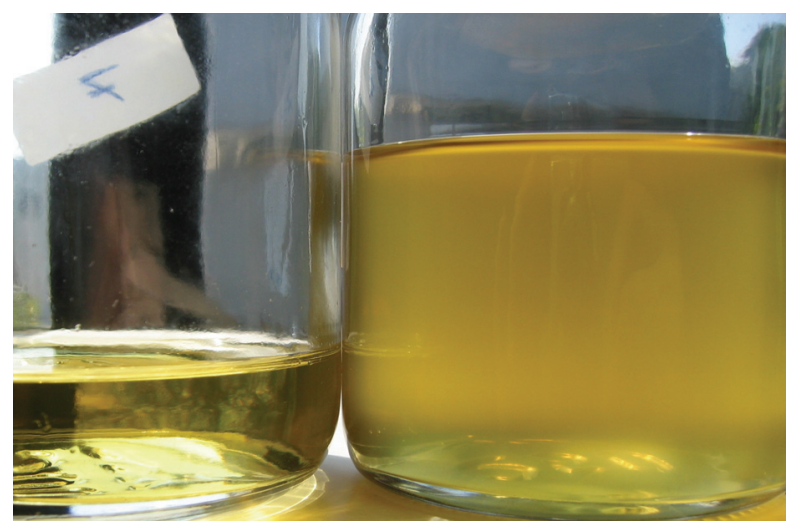

Fig. 3 Cloudy reaction products (right container)

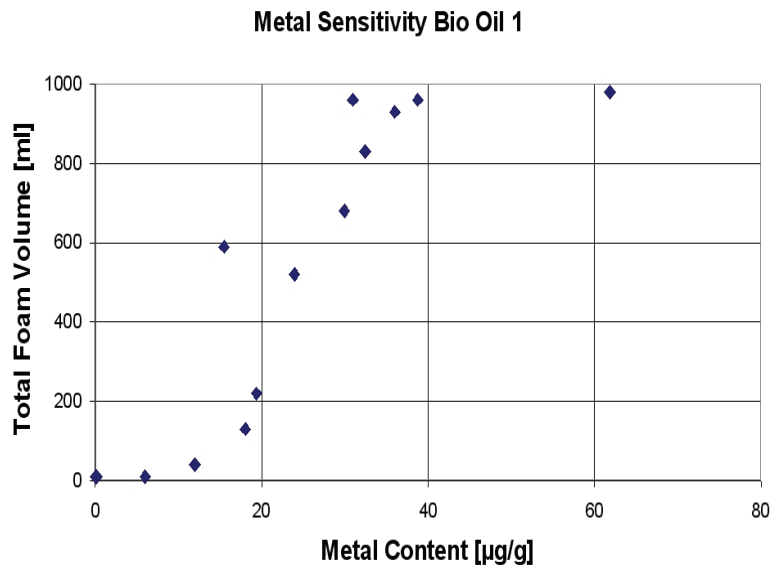

Fig. 4 Foam test result depending on metal content ${ }^{9)}$

To avoid technical problems, the ISO 15380 standard recommends a maximum contamination level of not more than $2 \%$ mineral oil content. This is a very rough estimate - in reality every combination of products reacts differently.

Technical instructions for changeover must therefore include guidelines for flushing and quality control. Also during maintenance and refilling, accidental adding of mineral oil has to be prevented.

During conversion from mineral oil to bio-oil, such contamination may easily occur. With mobile equipment having only $60 \%$ of its oil volume in the tank, and $40 \%$ distributed all over the hydraulic system, it is obvious that draining the tank is not enough.

In order to achieve the required $2 \%$ level of mineral oil residue, one or several flushing cycles are necessary. An example for a volume balance requiring several flush cycles to obtain the desired 2\% result is given in Figure 5 . In this example it is assumed that after draining $77 \%$, $23 \%$ of the old fluid still remain in the system. Better draining will reduce the number of cycles.

Flushing is very time consuming, expensive, and difficult to control. Future bio-oil development should therefore be focused on enhancing tolerance against substances present in mineral hydraulic oil.

Detailed instructions for changeover can be downloaded from the internet ${ }^{3)}$ or be obtained from the author.

Flushing Volume Balance (77\% Draining Efficiency)

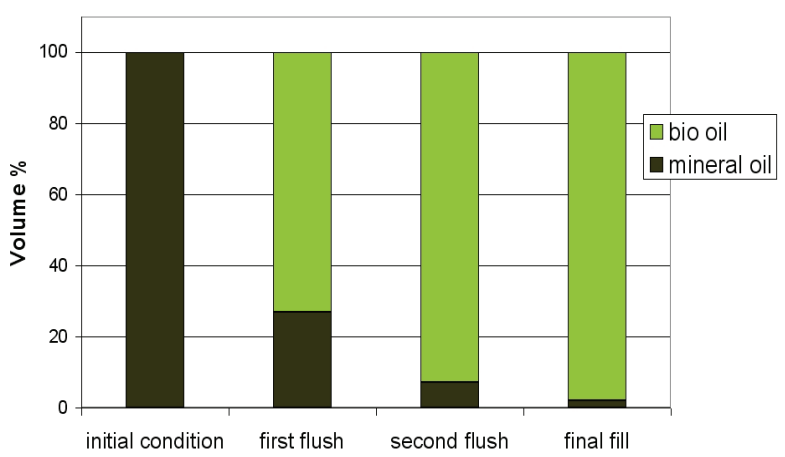

Fig. 5 Volume balance for multiple flushing cycles

\section{Economy}

As a consequence of the high loss risk of pressure fluid, the most important market for bio-lubricants is the mobile hydraulics market. Biodegradable hydraulic oil costs three to five times more per liter than mineral oil. However, if good filtering and maintenance is provided, an oil fill can last very long, and the oil related cost per operating hour of mobile equipment decreases, as shown in fig. 6.

With longer oil change intervals, the difference of the operating cost between both types of oil becomes

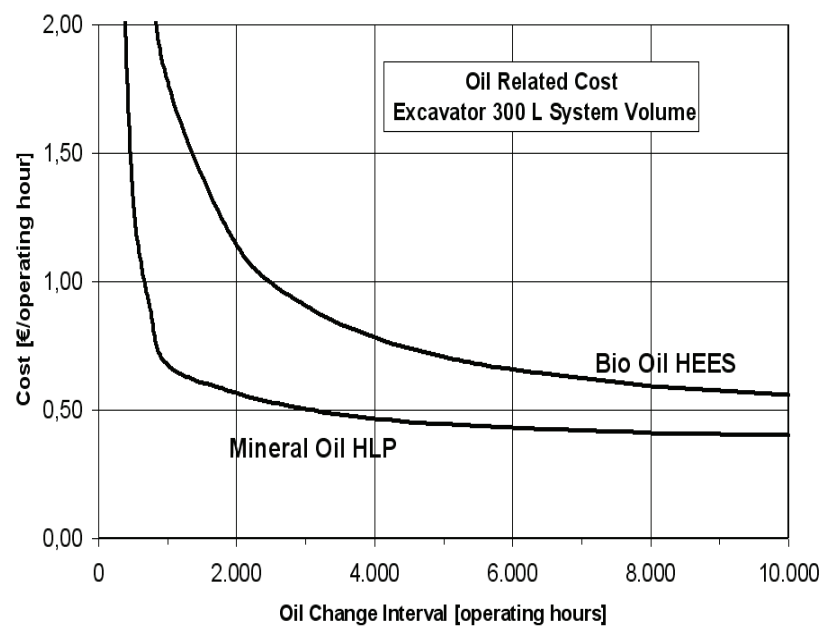

Fig. 6 Cost comparison bio-oil vs. mineral oil 
negligible - a few cents per operating hour for a mid-size excavator. It may even be lower with bio-oil when the risk of environmental damage and the reliability of a cleaner machine are taken into the account.

\section{Market reaction}

The market shares that have been achieved were shown above in Figure 1. More details were gathered in personal interviews by the author and in questionnaire surveys with suppliers, end users and other market constituents. The major motives to convert to biobased oil were its biodegradability and reduced risk in case of spills, leading to a "green image" and to additional business, especially for construction and forest service companies. The property of renewability and resource conservation was generally not considered important for the purchasing decision.

On the other hand, the major thresholds to market introduction were investigated in a survey done by TaT Rheine $^{10)}$ in Germany with both hydraulic experts and end users. It showed that the major problems were (1) lack of knowledge, (2) fear of technical problems, and (3) the high price per liter ranking last.

The market success in Germany showed a strong geographical bias towards the southern states. In these two states (Bavaria and Baden-Wuerttemberg) with only $25 \%$ of Germany's population, $60 \%$ of the biodegradable oil sales took place, as can be seen in Figure 7. It is obvious that a certain minimum presence of bio-oil supply in a geographical area is needed to provide examples, references, experienced sales force, second vendors, etc. and to overcome the above mentioned thresholds.

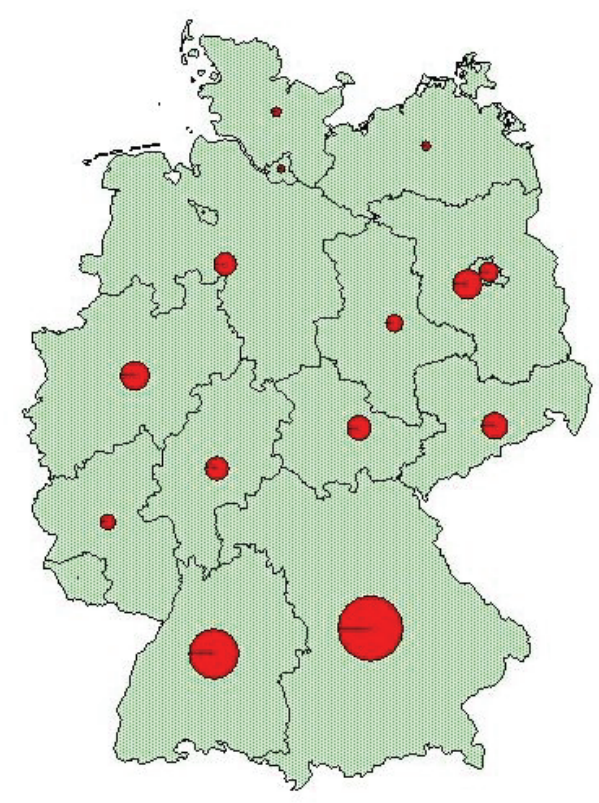

Fig. 7 Unbalanced geographical sales distribution of biobased oil in Germany ${ }^{11)}$
The successful introduction of biobased lubricants in Germany, and the low degree of technical problems with end users, has led the European Commission to introduce a biobased content requirement into its new "Euromarguerite" ecolabel for lubricants, that eventually may replace some of the national ecolabels - see Figure 8.

Finally, an IFAS survey among 250 end users (200 answers received) showed a $94 \%$ positive experience and general satisfaction with biobased lubricants, as shown in Figure 9.

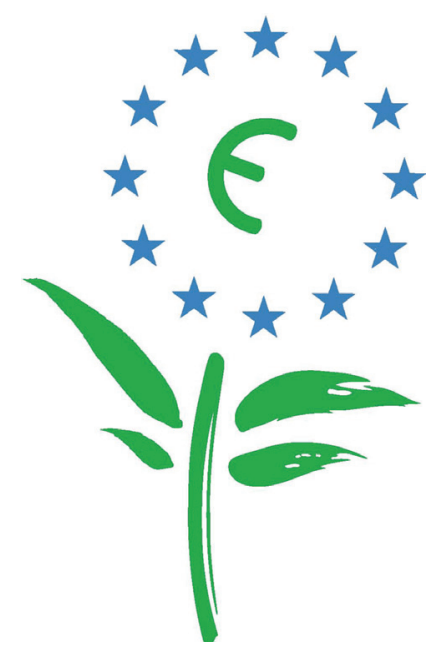

Fig. 8 European Ecolabel "Euromarguerite"

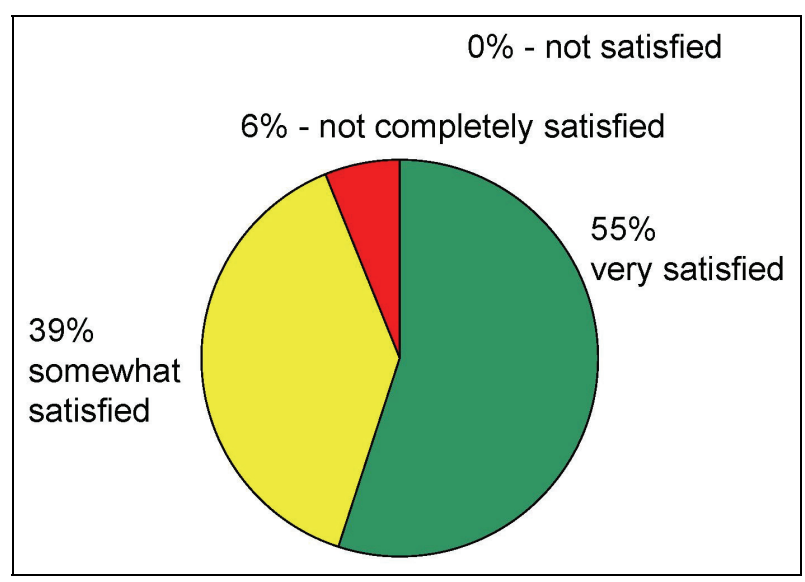

Fig. 9 Customer reactions ${ }^{12)}$

\section{References}

[1] ISO 15380 "Lubricants, industrial oils and related products (class L) - Family H (Hydraulic systems) Specifications for categories HETG, HEPG, HEES, and HEPR," 2002.

[2] OECD 301 "OECD Guideline for Testing of Chemicals," 1992.

[3] Internet pages of the Market Introduction Program: http://www.bioschmierstoffe.info/ (in German) 
[4] Theissen, H., "The Market Situation of BiodeGradable and Biobased Lubricants in Germany 2006," Aachen 2006, http://www.bioschmierstoffe.info. (in German)

[5] ASTM D 6866 - 04a: "Standard Test Methods for Determining the Biobased Content of Natural Range Materials Using Radiocarbon and Isotope Ratio Mass Spectrometry Analysis," 2004.

[6] Meindorf, T. and Theissen, H., "Fast Recognition of Bio-Oil," o + p Ölhydraulik und Pneumatik 53, 2009, 9, 390-394. (in German)

[7] Tobisch, R., "Long Term Forestry Testing of New Biobased, Biodegradable High Performance Hydraulic Fluids with Eco-Toxicologically Uncritical Additives," Final report (FNR FKZ 01NR085), KWF Groß-Umstadt, 2005. (in German)
[8] Kempermann, C., "Selected Measures to Improve Operating Conditions for Environmentally Friendly Pressure Fluids," Doctoral Diss. RWTH Aachen University, 1999. (in German)

[9] Theissen, H., "Effects of Contamination of Biobased Hydraulic Fluids with Mineral Oil," JAI Journal ASTM International, 6, 2009, 1. http://www2.astm.org/DIGITAL_LIBRARY/JOU RNALS/JAI/PAGES/1245.htm

[10] Transferzentrum für angepasste Technologien $\mathrm{GmbH} \quad$ (TaT), Rheine (Germany), http://www.tat-zentrum.de/

[11] Theissen, H., "Application of Bio-Oil in Hydraulics," o + p Ölhydraulik und Pneumatik 49(2005), 1, 47-52. (in German)

[12] Theissen, H., "Experiences with Bio Hydraulic Oil," o + p Ölhydraulik und Pneumatik 50, 2006, 3, 132-137. (in German) 